\title{
Upper mantle anisotropy beneath Japan from shear wave splitting
}

\author{
Maureen D. Long*, Rob D. van der Hilst \\ Department of Earth, Atmospheric, and Planetary Sciences, Massachusetts Institute of Technology, \\ Room 54-520, 77 Massachusetts Ave., Cambridge, MA 02139, USA
}

Received 2 March 2005; accepted 5 March 2005

\begin{abstract}
In this study, we utilize data from 64 broadband seismic stations of the Japanese $F$-net network to investigate the threedimensional pattern of anisotropy in the subduction system beneath Japan. We have compiled a database of approximately 1900 high-quality splitting measurements, selected by visual inspection of over 25,000 records of $S, S K S$, and $S K K S$ phases at $F$-net stations, covering a wide range of incidence angles, incoming polarization angles, and backazimuths. Analysis of the variations of measured splitting parameters with these parameters allows us to consider complexities in structure such as multiple anisotropic layers, dipping symmetry axes, and small-scale lateral variations in anisotropic properties. Here we focus on the presentation of the splitting measurements themselves; a detailed interpretation in terms of tectonics and mantle flow is beyond the scope of this paper.

In the southern part of the $F$-net array, along the Ryukyu arc, we find that fast directions are consistently trench-parallel, with splitting times of $1 \mathrm{~s}$ or more. Moving northward along the array, the measured splitting patterns become more complicated, with significant variations in apparent splitting parameters that indicate complex anisotropic structure. Additionally, measured fast directions vary significantly over short length scales, and stations separated by less than $100 \mathrm{~km}$ often exhibit very different splitting behavior. This increase in complexity of anisotropic structure coincides geographically with the complicated slab morphology of the subducting Pacific plate. At stations on Hokkaido, to the north, and Kyushu, to the south, we see some evidence that the fast direction of anisotropy may rotate from trench-parallel close to the trench to subduction-parallel further away from the trench, which may correspond either to a change in stress conditions and/or volatile content, or to a change in flow regime.
\end{abstract}

(C) 2005 Elsevier B.V. All rights reserved.

Keywords: $S$-wave splitting; Anisotropy; Upper mantle; Japan

\section{Introduction}

Elastic anisotropy in the Earth's mantle can manifest

* Corresponding author. Tel.: +1 6172533589; fax: +16172589697 .

E-mail address: mlong@mit.edu (M.D. Long). itself in the azimuthal dependence of body and surface wave propagation speed (Hess, 1964; Forsyth, 1975), a discrepancy between propagation speeds of Love and 
Rayleigh waves (e.g., Crampin, 1977), and shear wave splitting or birefringence (e.g., Savage, 1999). Seismic anisotropy is often assumed to have hexagonal symmetry (i.e., transverse isotropy) with an axis of symmetry that is either horizontal (i.e., azimuthal anisotropy) or vertical (i.e., radial anisotropy), but other orientations may, of course, occur. Seismic anisotropy in the upper mantle is a consequence of the strain-induced crystallographic or lattice preferred orientation (LPO) of intrinsically anisotropic mantle minerals, principally olivine. The relationships between deformation and LPO in olivine have been explored experimentally (e.g., Zhang and Karato, 1995) and theoretically (e.g., Tommasi et al., 2000; Kaminski and Ribe, 2001), and can also be inferred from petrographic examination of mantle-derived rocks (e.g., Christensen, 1984; Nicolas and Christensen, 1987). With known or assumed relationships between tectonic processes and strain, on the one hand, and between strain and anisotropy (through LPO), on the other, observations of seismic anisotropy can provide us with information about causes, mechanisms, and consequences of deformation in Earth's interior (Silver, 1996). Shear wave splitting measurements are an especially powerful tool for characterizing anisotropy because birefringence is an unambiguous indicator of anisotropy (Babuška and Cara, 1991).

We aim to use shear wave splitting to investigate subduction-related processes - e.g., stress generation and accommodation of deformation, melt production, and migration - in the upper mantle. These processes are still poorly understood and even the actual pattern of mantle flow above and below slabs of subducted lithosphere is not well known. Knowing the distribution of seismic anisotropy can help address these issues (e.g., Park et al., 2002). The presence of anisotropy in the upper mantle beneath subduction zones has been well established (e.g., Ando et al., 1983; Fischer and Yang, 1994; Hiramatsu and Ando, 1996; Fouch and Fischer, 1996; Iidaka and Obara, 1997; Fischer et al., 1998, 2000; Park and Levin, 2002). A diverse range of splitting behavior has been associated with different subduction zones. Both trench-parallel and trenchperpendicular fast directions have been inferred (e.g., Russo and Silver, 1994; Park and Levin, 2002), whereas at other stations above subduction zones no splitting is observed (Fischer et al., 1998).

Shear wave splitting measurements can provide a powerful tool for characterizing upper mantle deformation but their interpretation is particularly difficult in subduction zone settings. There is a diverse range of processes that could potentially affect the three-dimensional anisotropic structure of subduction zones, including corner flow in the mantle wedge induced by viscous coupling between the slab and wedge material, trench-parallel flow in the mantle wedge (due to transpression) or beneath the slab (due to slab rollback), formation and migration of melt, flow around the slab edge, frozen lithospheric anisotropy in the slab, and anisotropic structure in the overriding plate. Additionally, new experimental studies suggest that the relationships between strain and resulting LPO can be dramatically altered by the presence of a small amount of water or other volatiles (Jung and Karato, 2001; Karato, 2004) or by the presence of melt (Holtzman et al., 2003). Subduction-associated processes, therefore, are likely to lead to anisotropic structures that are more complicated than the simple single-layer anisotropic models that are often assumed when interpreting splitting measurements. Various studies have explored the effects of more complicated anisotropic models on splitting measurements, such as multilayered anisotropy (Fryer and Frazer, 1984, 1987; Silver and Savage, 1994; Özaleybey and Savage, 1994; Levin et al., 1999, 2000), dipping symmetry axes (Hartog and Schwartz, 2000; Chevrot, 2000; Chevrot and van der Hilst, 2003), and smooth variations in fast axis orientation with depth (Saltzer et al., 2000). However, the interpretation of shear wave splitting measurements in the presence of complicated three-dimensional anisotropic structure remains extremely difficult and non-unique.

Our long-term goal is to meet these challenges by a rigorous integration of seismological data analysis and geodynamical (flow) modeling. Japan, the geographical region of our primary interest, is well suited for such an approach. First, the region is very well instrumented because of the need for continuous monitoring of seismic and volcanic activity, and data from several broadband seismic networks are freely available. Second, it is fairly well located with respect to both global seismicity (especially for teleseismic events in the $40-80^{\circ}$ epicentral distance range, although azimuthal coverage for events at $85^{\circ}$ and beyond is considerably poorer) and local seismicity from slab earthquakes. Third, the slab morphology associated with the subduction of the Pacific and Philippine plates beneath Eurasia (Fig. 1) is known from travel time tomography (e.g., van der 


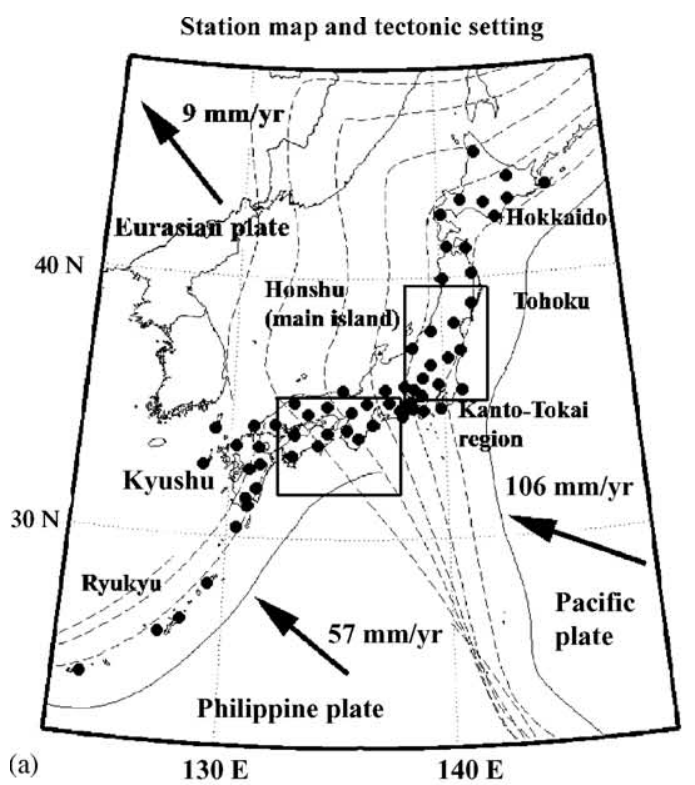

(a)

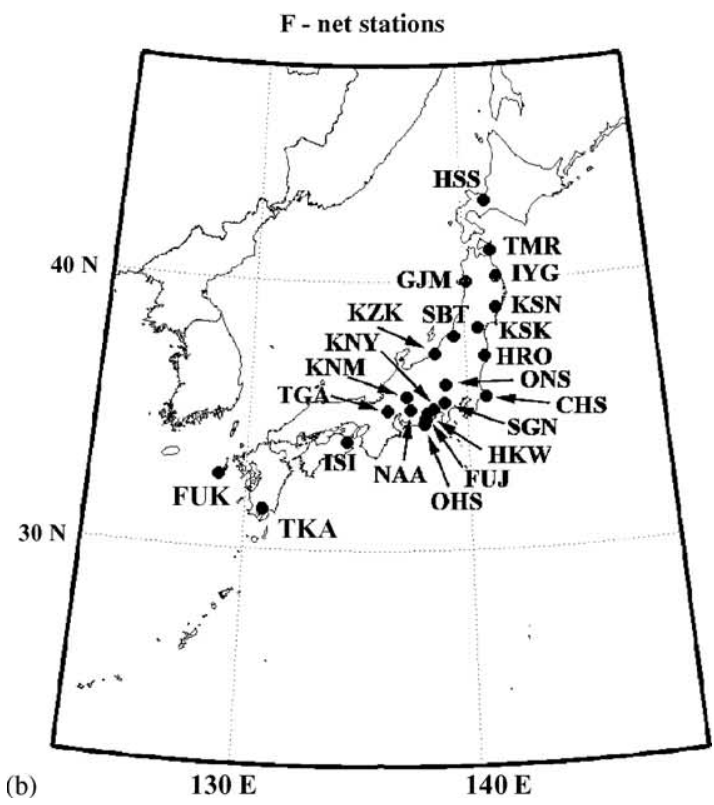

Fig. 1. (a) Station map for $F$-net, along with relevant tectonic features. Circles indicate the locations of $F$-net stations as of mid-2002. The locations of trenches (solid lines) and slab contours at $100 \mathrm{~km}$ intervals (dotted lines) are shown, after Gudmundsson and Sambridge (1998) and Engdahl et al. (1998). Arrows indicate the directions of plate motions, and rectangles indicate the study areas of Nakajima and Hasegawa (2004) (top) and Smith and Fouch (submitted for publication) (bottom). (b) The locations of all $F$-net stations mentioned by name in the text.
Hilst et al., 1991; Fukao et al., 1992) and seismicity (e.g., Engdahl et al., 1998; Gudmundsson and Sambridge, 1998).

As a first step toward achieving the long-term goal, we present here a large dataset of shear wave splitting measurements from $F$-net, a network of 64 broadband stations in Japan (Fig. 1), and establish evidence for complex anisotropic structure in the upper mantle beneath the array. In the denser parts of the network, the average station spacing is of the order of 70-80 km (equivalent to the station spacing envisioned for the USArray component of Earthscope). Our splitting database contains approximately 1900 measurements, with as many as 55 high-quality measurements for individual stations. We explore in detail the dependence of splitting on backazimuth, incoming polarization azimuth, and incidence angle. We address several specific questions. What are the characteristic splitting patterns at $F$-net stations, and what is the range of splitting behavior over the array? Over what spatial length scales does splitting behavior change or stay constant, and what can this tell us about different styles of deformation in the upper mantle? Are splitting patterns at $F$-net stations generally consistent with simple, single-layer anisotropic models, or do we see evidence for complexity in anisotropic structure beneath Japan? Do features of the splitting map for the $F$-net network correlate with tectonic features? What do our $F$-net splitting results tell us generally about interpreting splitting measurements in subduction zone environments?

\section{Events used in this study}

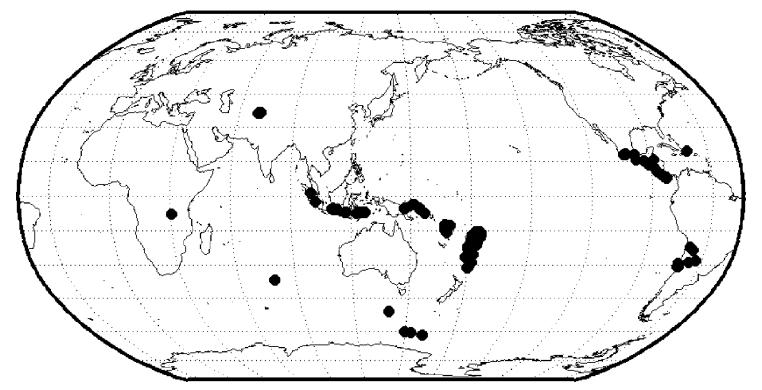

Fig. 2. A map of events used in this study, March 1995May 2004. 


\section{Data and methods}

We utilize data from $F$-net (Fig. 1), a network of 82 broadband stations that is administered by the Japanese National Research Institute for Earth Science and Disaster Prevention (NIED). We have processed data for a subset of 64 stations of the $F$-net array, which were installed in or before 2001 and were collectively known as the FREESIA array. The first $F$-net stations were installed in early 1995. $F$-net data is made available on the web by NIED (www.fnet.bosai.go.jp). Despite relatively high levels of cultural noise in Japan and the proximity of many $F$-net stations to the ocean, the data quality for $F$-net stations is very high and we found only three stations (TYM, TTO, and IWT) with insufficient data quality to carry out a detailed splitting analysis.

We have selected recordings of teleseismic direct $S$ phases for epicentral distances from 40 to $80^{\circ}, S K S$ from 85 to $120^{\circ}$, and $S K K S$ from beyond $105^{\circ}$. At some stations we have also analyzed local $S$ phases from deep slab earthquakes. A map of events used in this study is shown in Fig. 2. Coverage for SKS and SKKS is restricted to certain backazimuthal ranges, but backazimuthal coverage for direct $S$ phases is adequate, and, in addition, there is abundant local seismicity. We con-

Processing of an SKS recording at station SGN

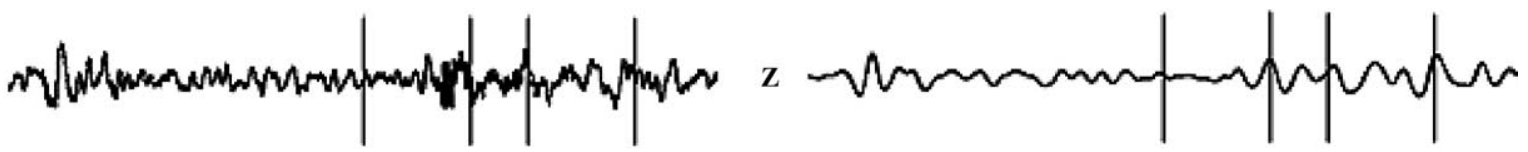

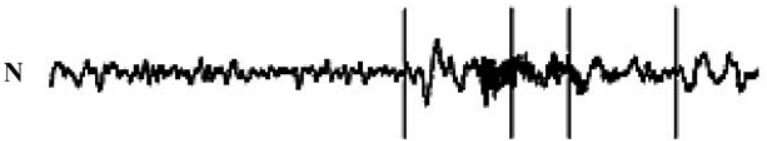

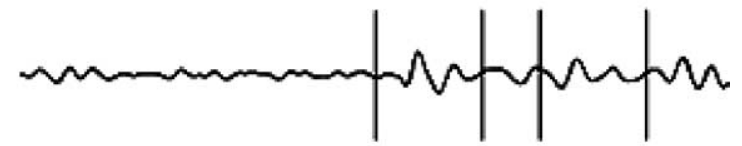

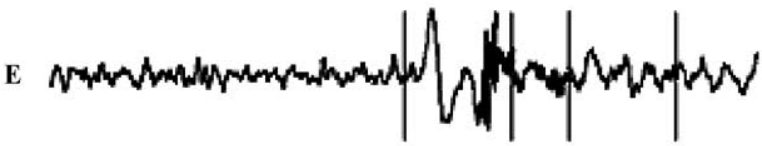

E

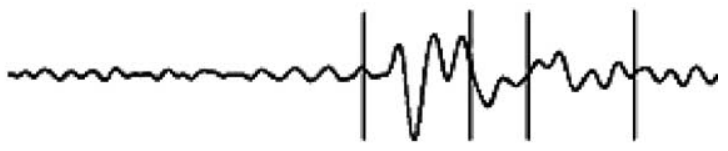

(A)

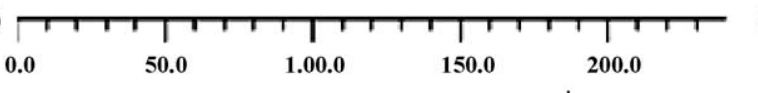

(B)

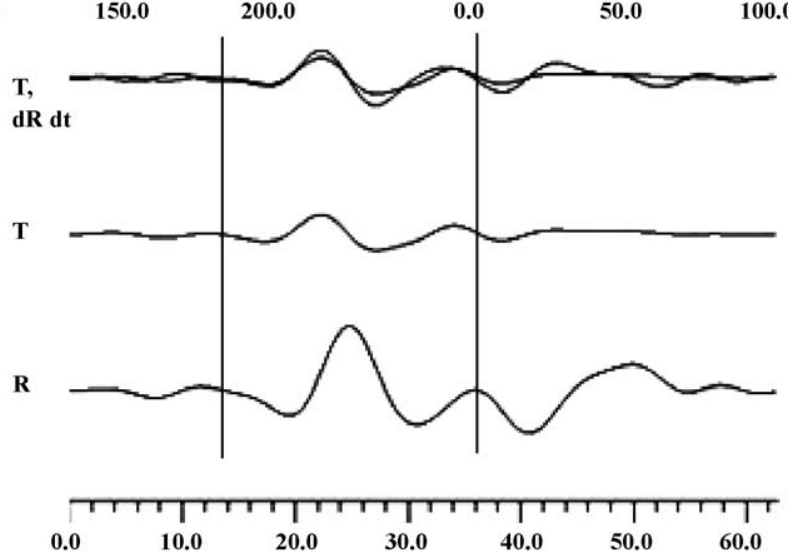

(C)

Fig. 3. (A) A raw, unfiltered seismogram at station SGN, with the expected arrival times for $S K S$ (ac), $S K S$ (df), $S K K S$, and $S d i f f$ from the iasp91 earth model shown. (B) The record has been bandpass filtered between $0.02 \mathrm{~Hz}$ and $0.125 \mathrm{~Hz}$. A clear $S K S$ arrival can be seen. (C) The seismogram has been deconvolved (see Chevrot, 2000) and windowed around the SKS phase; the radial (bottom) and transverse (middle) components are shown. In the top trace, the transverse component is overlain with the time derivative of the radial component. As expected, the shape of the transverse component matches the derivative of the radial component. Vertical bars indicate the time window used in the splitting analysis. 
Splitting at $6 \mathrm{~F}$-net stations
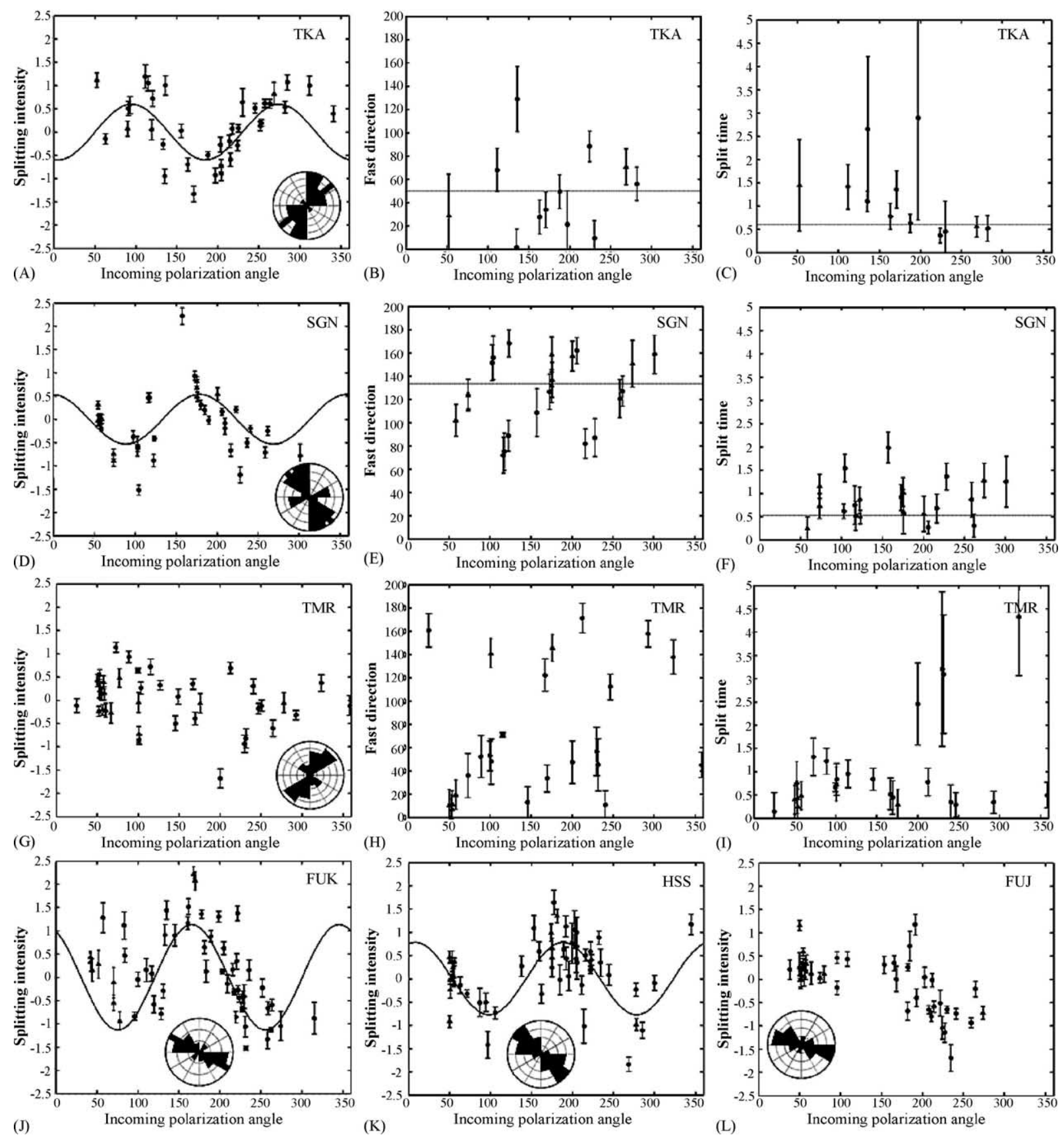
sider splitting from these different types of shear wave phases together; these phases take very different raypaths through the mantle and/or core, but they sample the region beneath the stations in a very similar way. A justification for this approach, which has been followed by previous studies (e.g., Hartog and Schwartz, 2000), is contained in Section 4.1. For teleseismic $S$ phases, we restrict our search to deep ( $>200 \mathrm{~km}$ ) events to reduce contamination from near-source anisotropy. For direct $S$ phases, the polarization vector of the incoming wave is determined directly from the seismogram by measuring the direction of maximum polarization (Vidale, 1986). We apply a four-pole Butterworth bandpass filter with corner frequencies at $0.02 \mathrm{~Hz}$ and $0.125 \mathrm{~Hz}$ to the data, and window around the phase of interest based on the predicted traveltimes from the iasp 91 earth model (Kennett and Engdahl, 1991). Records were visually inspected for good signal-to-noise ratio and waveform clarity; we compared the shapes of the radial and transverse waveforms to ensure that energy on the transverse component conforms to expectations for anisotropy. A recording of an SKS arrival at station SGN in various stages of processing is shown in Fig. 3.

In order to be able to recognize complex anisotropy better and obtain robust estimates of splitting parameters we use two complementary methods for estimating the shear wave splitting parameters $\varphi$ and $\delta t$ (the polarization direction of the fast shear arrival and the time separation between the orthogonal components, respectively). For a detailed explanation of the splitting methods used we refer to Long and van der Hilst (in press), but for the sake of completeness we summarize them here. The cross-correlation method (Fukao, 1984, and others; we use the implementation due to Levin et al., 1999) yields an estimate of $\varphi$ and $\delta t$ from the horizontal components of a single seismogram by grid-searching for the inverse splitting opera- tor that maximizes the similarity in the pulse shapes of the corrected horizontal seismogram components (which therefore maximizes their cross-correlation). The second method, due to Chevrot (2000), uses the variation of the amplitudes of the transverse components with incoming polarization angle (which for core-refracted phases such as $S K S$ is equivalent to the backazimuth). For a homogenous layer of anisotropy with a horizontal axis of symmetry the amplitude of the transverse seismogram component $T(t)$ is given by:

$$
T(t) \approx-\frac{1}{2}(\delta t \sin 2 \beta) R^{\prime}(t)
$$

where $R^{\prime}(t)$ is the time derivative of the radial waveform and $\beta$ is the angle between the incoming polarization vector $\boldsymbol{p}$ and the fast direction $\varphi$. The ratio of the transverse amplitude to the amplitude of the time derivative of the radial component as a function of incoming polarization angle is known as the splitting vector; in the case of a single horizontal anisotropic layer we can retrieve $(\varphi, \delta t)$ from the phase and amplitude of the $\sin (2 \theta)$ curve that best fits the observed splitting vector. If the anisotropy is more complex, the splitting vector would not show a simple sinusoidal behavior and the $(\varphi, \delta t)$ determined with the crosscorrelation method would depend on backazimuth (or $\boldsymbol{p}$ for direct waves). In this case, the measured splitting parameters are merely "apparent" measurements and must be interpreted with complex anisotropy in mind.

\section{Splitting results}

\subsection{Splitting patterns at individual stations}

For each of the $64 F$-net stations we have measured apparent splitting parameters as a function of incom-

Fig. 4. The results of the splitting analysis using the Chevrot (2000) method (A) along with measured fast directions (B) and split times (C) using the cross-correlation method, for station TKA. In panels (D-F) and (G-I), we show the results for stations SGN and TMR, respectively. In panels (J-L), we display the Chevrot (2000) results only for stations FUK, HSS, and FUJ. All error bars are $2 \sigma$. All plots of the Chevrot splitting vector include a rose diagram (inset) showing the distribution of fast directions found with the cross-correlation method. Gray bars on the rose diagram indicate the best fit from the Chevrot (2000) method. Direct $S$ phases are marked with a circle; core-refracted phases are marked by a triangle. Each plot shows the relevant splitting parameter plotted against the incoming polarization angle, which is equivalent to the backazimuth for $S K(K) S$ phases. For direct $S$ phases, the polarization angle $\left(0-180^{\circ}\right)$ was measured directly from the seismogram. Measured polarization angles for events with a backazimuth in the range $90-270^{\circ}$ were then adjusted by adding $180^{\circ}$, so that events with similar polarizations but widely different polarizations will plot $180^{\circ}$ apart. This convention makes the splitting patterns easier to visualize, but in no way changes their interpretation. 
ing polarization angle. Because of the excellent data coverage, with some stations having as many as 55 good recordings, we are able to characterize the splitting patterns in great detail. For six stations (marked on Fig. 1), which are representative of the wide range of splitting behavior present at $F$-net stations, we show in Fig. 4 the results of both the Chevrot (2000) and the cross-correlation method. It is obvious from a visual inspection of Fig. 4 that a wide range of splitting behavior is observed at $F$-net stations. For stations FUK and TKA (see Fig. 1 for station locations) the Chevrot (2000) splitting vector is fit very well with a $\sin (2 \theta)$ curve, and the measured fast directions $\varphi$ and split times $\delta t$ obtained from the cross-correlation method show no systematic variation (and little scatter) with incoming polarization azimuth. The average splitting parameters obtained with the cross-correlation method agree well with the $(\varphi, \delta t)$ retrieved from the Chevrot (2000) splitting vector. At stations TMR and FUJ, however, the measured splitting patterns are strikingly different from the simple splitting behavior at FUK and TKA. Although there is ample evidence for splitting and, therefore, for anisotropy, significant variations in apparent splitting with incoming polarization angle are present in both the Chevrot (2000) and crosscorrelation measurements. These observations suggest that the anisotropy beneath TMR and FUJ is complicated. The remaining two stations shown in Fig. 4, SGN and HSS, exhibit splitting behavior that is somewhat in between the two endmember cases; at both of these stations there is significant variation in measured splitting parameters with incoming polarization azimuth, but a significant part of the splitting signal appears to be consistent with a simple anisotropic model, and it is possible to find average splitting parameters that explain the main features of the splitting pattern.

\subsection{Geographical variations in splitting parameters}

We synthesize our database of over 1900 splitting measurements into a map of geographical variations of shear wave splitting for $F$-net. This map is shown in Fig. 5, along with contours of Wadati-Benioff seismicity at $100 \mathrm{~km}$ intervals. We have somewhat arbitrarily divided the stations into four categories: (I) splitting behavior consistent with a single horizontal anisotropic layer (e.g., FUK and TKA, Fig. 4); (II) splitting pat-

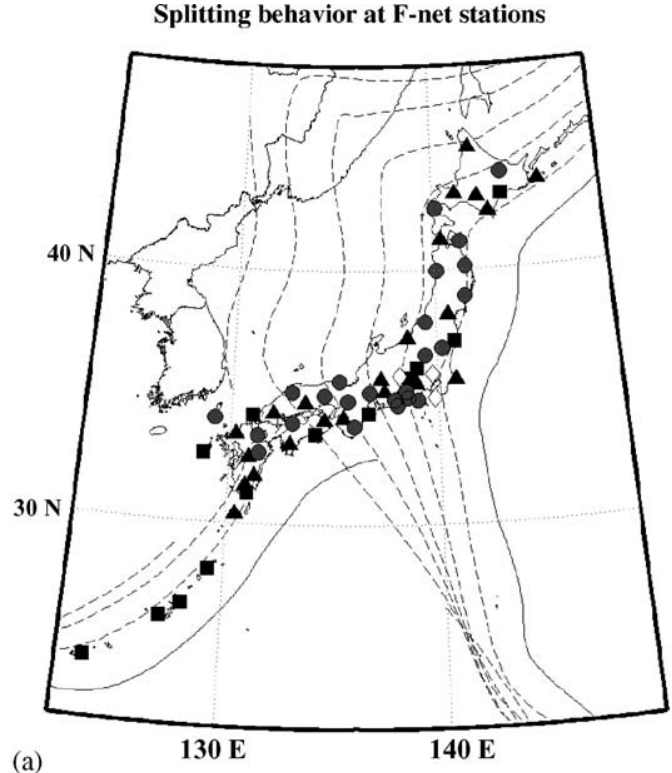

(a)

Splitting map for F-net

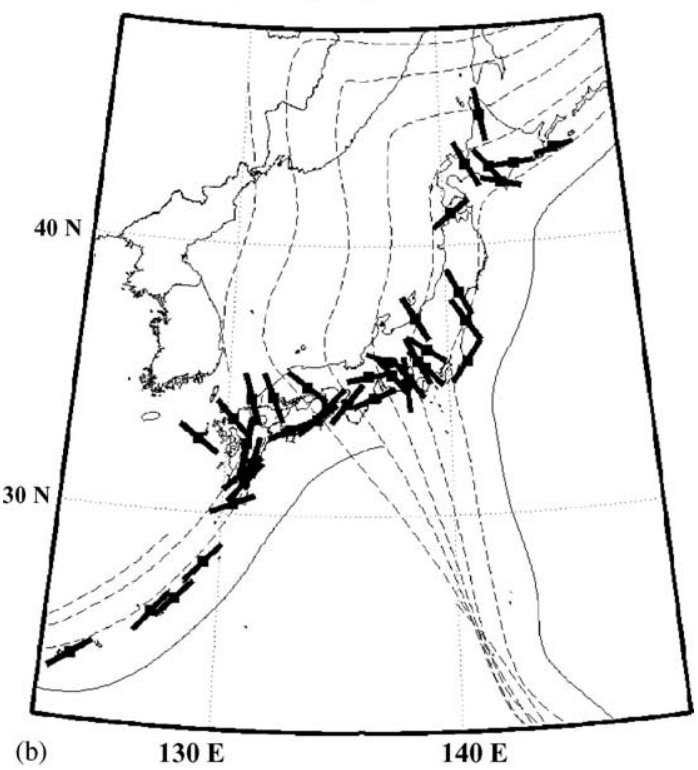

Fig. 5. (a) A map of the types of splitting behavior observed at $F$-net stations. At stations marked with a black square, the splitting behavior is Category I (see text) and is consistent with a simple anisotropic model. Category II stations are marked with a black triangle. At stations marked with a gray circle, the splitting behavior is Category III and is inconsistent with a simple model. Category IV stations, for which the data quality is poor, are marked with an open diamond. (b) A map of fast directions at $F$-net stations. We plot a fast direction for all Category I and Category II stations. 
tern deviates from a simple anisotropic model, but meaningful average splitting parameters can still be extracted (e.g., SGN and HSS, Fig. 4); (III) evidence of anisotropy, but splitting pattern deviates strongly from the predictions of a simple model and complex anisotropic structure is very likely present (e.g., TMR and FUJ, Fig. 4); (IV) data quality is insufficient. Category II can be thought of as an "intermediate" category between "simple" (Category I) and "complex" (Category III) stations. For stations in Category II we do compute average splitting parameters and we do expect them to have physical meaning, but we recognize that there is probably a slight deviation from a perfectly simple, homogeneous, single-layer anisotropic model. For example, it could imply an anisotropic layer with a slight dip, or a two-layer model where one layer is much thicker and/or more anisotropic than the other. We recognize that by computing average splitting parameters for Category II stations we are missing some subtle aspects of the anisotropy beneath the station. This is why we carefully distinguish between Category I and Category II stations and invest a greater degree of confidence in the average splitting parameters for Category I stations. For all stations in Category I and Category II, the average fast direction is indicated on the splitting map (Fig. 5). A summary of splitting behavior at all $F$-net stations can be found in the Appendix A, both in table form (Table A.1) and as a plot of circular histograms (rose diagrams) showing the distribution of measured fast directions at each station (Fig. A.1).

The splitting map for the $F$-net network exhibits several intriguing geographical variations. First, there is much variability in the character of splitting behavior from station to station, and in some regions shear wave splitting changes dramatically over lateral distances as small as $50 \mathrm{~km}$. A Fresnel zone argument (e.g., Alsina and Snieder, 1995) would suggest that at least some of the observed signal has a shallow mantle origin. In the southernmost part of the array, along the Ryukyu arc, the fast directions are consistently trenchparallel. Moving northward along the array into the central Kanto-Tokai region, the splitting behavior becomes more complicated and small-scale spatial variations become more pronounced. Both the measured fast directions and the character of splitting patterns vary rapidly over this part of the network, although many stations in the central part of the array exhibit a fast direction trending roughly NW-SE. In northern Honshu, nearly all stations exhibit a higher degree of complexity than the stations in the southern part of the array, which coincides geographically with the complex morphology of the Marianas-Japan-Kuril slab compared to the simple morphology of the Philippine slab. In the northernmost part of the array, on Hokkaido, the fast directions seem to rotate from trench-parallel for stations vertically above the $100 \mathrm{~km}$ depth contour of the slab, to trench-perpendicular for stations located farther to the northwest of the trench.

\section{Discussion}

\subsection{The range of splitting behavior at F-net stations: implications for deformation}

At several $F$-net stations we observe splitting patterns that are consistent with a single horizontal anisotropic layer, but most stations exhibit more complexity. Some of this complexity may be due doublelayer anisotropy, e.g., beneath SGN. The range in splitting behavior observed at $F$-net stations argues for a range of possible anisotropic structures beneath the Japanese islands, and for a range of deformation styles or geometries. In some areas, most notably the KantoTokai region where slab morphology is most complicated, stations that are separated by less than $70 \mathrm{~km}$ often exhibit totally different splitting behavior. This could be attributed to very shallow anisotropy, based on a Fresnel zone argument (Alsina and Snieder, 1995; Favier and Chevrot, 2003), or it could be a consequence of lateral heterogeneity in anisotropic structure on very short length scales. In other areas, most strikingly along the Ryukyu arc, we observe splitting patterns that are remarkably consistent over $\sim 700 \mathrm{~km}$ length scales. This geographic coherence in splitting behavior is likely a result of large-scale coherence of upper mantle flow patterns or other anisotropy-generating mechanisms.

\subsection{Does splitting result primarily from upper mantle anisotropy?}

Because shear wave splitting is a path-integrated measurement, without additional information it is impossible to deduce the location of the anisotropy along the path from a single measurement. We explain here 
why we neglect contributions from the crust, the lower mantle, and near-source structure.

First, we note that although the ray geometry for the different types of phases used $(S, S K S$, and $S K K S$ ) are quite different, their raypaths through the anisotropic upper mantle beneath the array are nearly identical and they sample the anisotropic region in nearly the same way. It is probable that our measurements contain some signal from crustal anisotropy, as crustal rocks are often anisotropic and can frequently have intrinsic shear wave anisotropy approaching $~ 50 \%$ (e.g., Crampin, 1977). However, the split times attributed to crustal anisotropy are typically much smaller than those attributed to upper mantle anisotropy (Silver, 1996; Savage, 1999) due to the much shorter path lengths in the crust compared to those in the upper mantle. Kaneshima (1990) studied shear wave splitting due to crustal anisotropy in Japan and found split times less than $0.2 \mathrm{~s}$, and typically less than $0.1 \mathrm{~s}$. We typically see a much larger split time (e.g., 0.70-1.5 s) at $F$-net stations, but we acknowledge that a small amount of contamination from crustal anisotropy is possible and, perhaps, likely.

Another possible source of contamination is a contribution from anisotropy in the lower mantle. We view this possibility as unlikely for two reasons. First, previous studies of mineral physics and seismological results (Meade et al., 1995; Niu and Perez, 2004) argue that most of the splitting of SKS-type phases, which travel from the core-mantle boundary to the surface on their receiver-side leg, can be attributed to upper mantle anisotropy beneath the receiver, with negligible contribution from $\mathrm{D}^{\prime \prime}$, the lower mantle, and the transition zone. A more persuasive argument comes from the dataset itself. We have used a similar geographical distribution of events at each $F$-net station, and the rays traveling from a given event to each station in the network have similar (and long) path lengths in the lower mantle. If lower mantle anisotropy made a significant contribution to teleseismic shear wave splitting, then we would see a great deal of coherence among the shear wave splitting patterns at each station. Instead, we observe that stations separated by short distances $(\sim 100 \mathrm{~km})$ often have completely different splitting patterns. This argues against a systematic contribution to the anisotropic signal from the lower mantle.
Next we consider possible contributions from nearsource anisotropy. Because most of the phases in our dataset are direct $S$ phases, this is a serious concern. In order to reduce the contamination by anisotropy in the shallow mantle near the source we restrict our dataset to events with hypocenter depths greater than $200 \mathrm{~km}$. However, anisotropy has been inferred to exist to depths as great as $400 \mathrm{~km}$ or perhaps deeper in subduction zone environments (e.g., Fouch and Fischer, 1996; Fischer and Wiens, 1996). If anisotropy near the deep sources considered has a detectable effect on our splitting measurements, we would expect (1) that this effect is similar for all stations of the array since the range of wave vectors associated with the deep events considered in our study is fairly small and (2) that omitting data from deep events would alter the inferred splitting parameters. We have investigated the possibility of both types of expression. First, we investigated for each deep earthquake the pattern of splitting parameters across the array. Only one deep event (beneath Tonga) produced a spatially coherent signal, with splitting of $\sim 1.5 \mathrm{~s}$ and a roughly $\mathrm{N}-\mathrm{S}$ fast direction. To reduce possible bias from near-source anisotropy from this event, we discarded data from this event. Any remaining long wavelength imprint due to distant source-side structure is unlikely to influence the character of the short wavelength variations of splitting parameters across the array. Second, we subdivided the set of deep events into four geographic regions and two depth ranges, and we inspected the effect on the splitting pattern at station HSS of omitting data from any of these source regions. The results of this test are presented in Fig. 6. In general, removal of data from different groups of events does not significantly change the inferred splitting parameters for this station. Only one group of intermediate depth $(z<400 \mathrm{~km})$ events beneath the Fiji-Tonga region may induce some complexity to the splitting pattern (Fig. 6), but even here the effect is small compared to the observed spatial changes in splitting parameters along the array. Finally, for stations in the Ryukyu arc we have measured splitting for both teleseismic and local slab events. These two types of measurements give very similar results, which precludes significant contamination from source-side or lower mantle anisotropy (see Fig. 7).

We conclude, therefore, that most of the splitting signal we observe at $F$-net stations results from anisotropy located in the shallow mantle beneath the re- 


\section{Source distribution for station HSS}

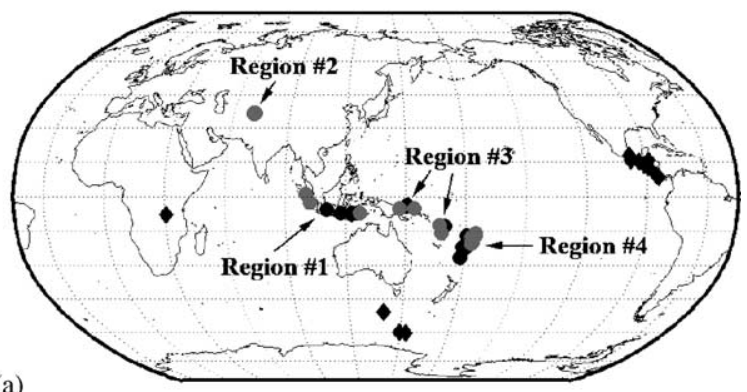

Splitting vector for station HSS

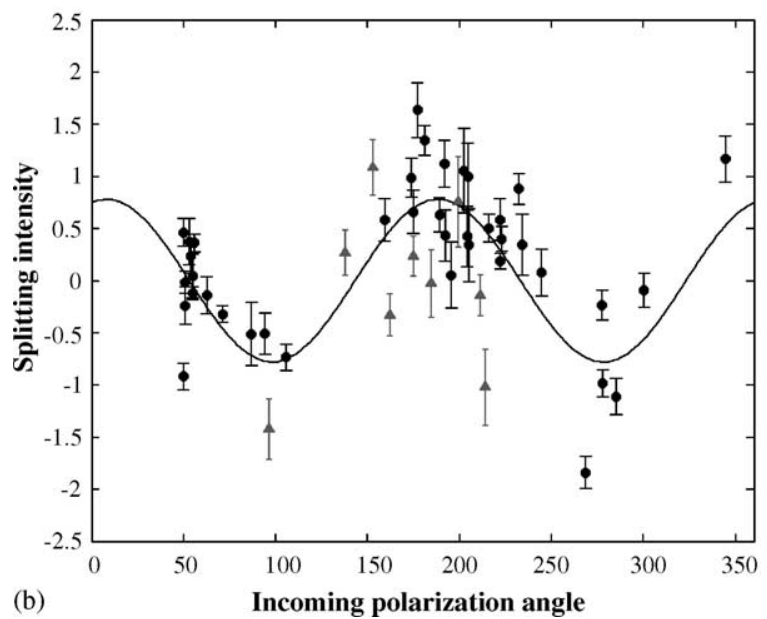

Fig. 6. (a) A map of the event distribution for station HSS, subdivided into regions used in the hypothesis testing described in Section 4.1. Direct $S$ events are indicated with circles; black circles indicate events deeper than $400 \mathrm{~km}$, and gray circles indicate events between $200 \mathrm{~km}$ and $400 \mathrm{~km}$ depth. $S K(K) S$ events are marked with diamonds. (b) The Chevrot (2000) splitting vector for station HSS. The splitting intensities for intermediate-depth events in the New Hebrides-Tonga-Kermadec subduction zone are plotted with gray triangles; all other events are plotted with black circles.

ceivers, and that contributions from the crust, the lower mantle, and near-source anisotropy for direct $S$ phases are negligible. By implication, data from direct $S$ and $S K(K) S$ phases can be interpreted jointly for the purpose of our study.

\subsection{Is anisotropy located primarily in the lithosphere or the asthenosphere?}

The relative contributions of lithospheric and asthenospheric anisotropy have been hotly debated (see
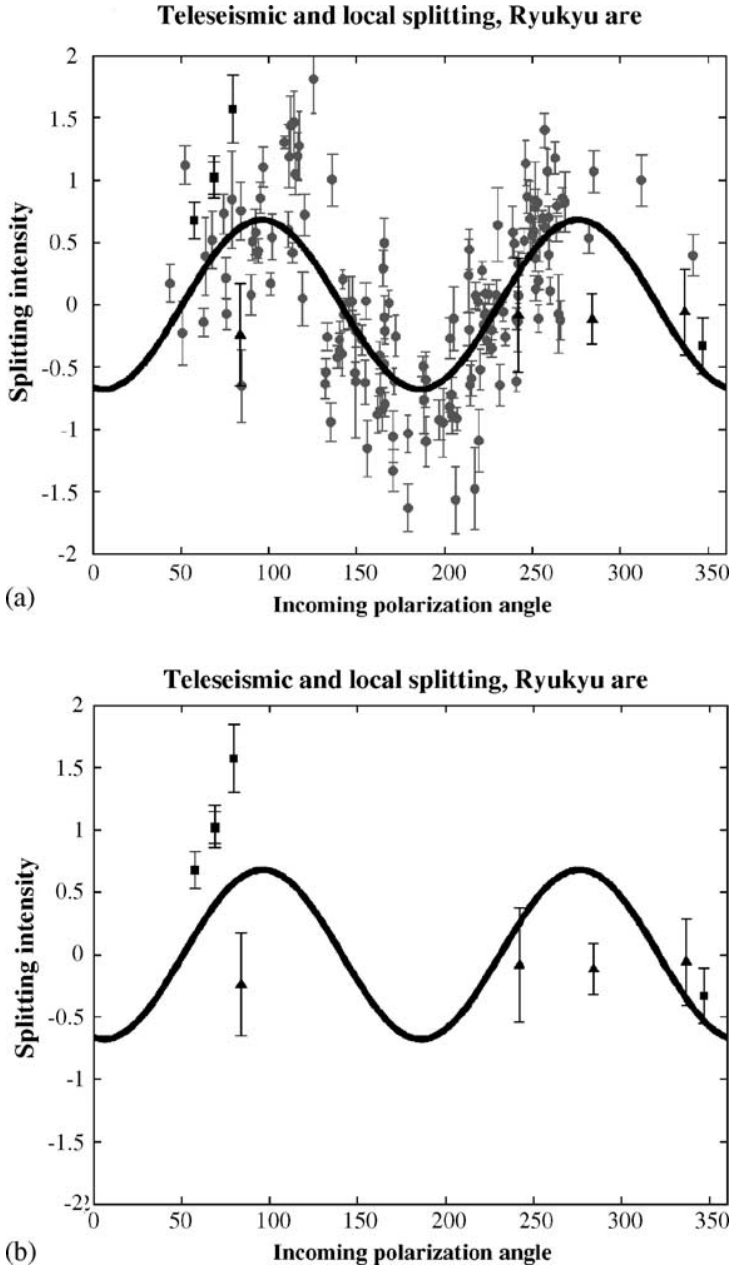

Fig. 7. (a) The combined teleseismic splitting vector for all Ryukyu arc stations is shown with gray circles. The dark line indicate the best $\sin (2 \theta)$ fit to the teleseismic splitting data. Also shown are the splitting results for nine local slab events; these results are plotted in black. (b) For clarity, the individual teleseismic splitting results have been removed and only local events are shown. The $\sin (2 \theta)$ fit is the same as shown in (a). Events with hypocenter depths between $50 \mathrm{~km}$ and $100 \mathrm{~km}$ are plotted as triangles; those deeper than $100 \mathrm{~km}$ are plotted as squares. All deep slab events are consistent with as much splitting (or more) than the average teleseismic splitting, while shallower slab events show little or no splitting. These results suggest that anisotropy is concentrated in the deeper part of the superslab mantle.

reviews by Silver, 1996 and Savage, 1999) and it is clear that in some continental regions contributions from both must be considered (e.g., Simons and van der Hilst, 2003). We cannot rule out contributions from 
the lithosphere, but for the current presentation of the results we assume that asthenospheric anisotropy contributes significantly to splitting observed at $F$-net. First, the magnitude of the splitting times for $F$-net stations (often larger than $1 \mathrm{~s}$ ) may be difficult to explain with lithospheric anisotropy alone, but would be consistent with the large deformation that can be expected at subduction zones. Second, there is significant observational evidence for an asthenospheric component in subduction zones worldwide (e.g., Fischer et al., 1998; Fischer and Wiens, 1996; Fouch and Fischer, 1996; Smith and Fouch, submitted for publication; Peyton et al., 2001, and others). Furthermore, for stations that are consistent with a simple anisotropic model (Fig. 5) we expect that there is either little contribution from lithospheric anisotropy or that the lithospheric and asthenospheric fast directions are closely aligned. The complexity observed at other stations could be due to a lithospheric contribution, however, and in our future modeling of the splitting parameters both the lithospheric and asthenospheric contributions will be investigated more quantitatively.

\subsection{Interpretation of F-net splitting in terms of tectonic features}

Perhaps the most striking feature of the $F$-net splitting map is the consistently trench-parallel fast directions along the Ryukyu arc (Fig. 5). It is worth noting that both trench-perpendicular and trench-parallel fast directions associated with subduction zone anisotropy have been observed in different parts of the world (e.g., Fouch and Fischer, 1996; Smith et al., 2001; Park and Levin, 2002; Levin et al., 2004). Three possible mechanisms have been suggested to generate trench-parallel fast directions above a subduction zone: trench-parallel flow above the slab, due to transpression of the overlying mantle wedge (Mehl et al., 2003), trench-parallel flow beneath the slab due to slab rollback or a similar mechanism (Peyton et al., 2001) or corner flow in the mantle wedge induced by viscous coupling with the downgoing slab, along with the presence of an "exotic" deformation-induced LPO pattern (Jung and Karato, 2001; Holtzman et al., 2003).

In an attempt to determine which of the above possibilities is most plausible we measured splitting from local events beneath the Ryukyu stations and compared the observed splitting from local events to the teleseis- mic splitting patterns (Fig. 7). While the usefulness of this comparison is limited by the number of local events located directly beneath Ryukyu stations, this comparison seems to rule out significant contributions from anisotropy beneath the slab. Additionally, it seems difficult to explain anisotropy in the mantle wedge with trench-parallel flow due to transpression, as the convergence direction at the Ryukyu arc is nearly perpendicular to the strike of the trench. Therefore, it seems that corner flow coupled with "unusual" LPO is the most likely mechanism for the trench-parallel fast directions in the southernmost part of the array.

A second striking feature in our dataset is the apparent rotation of the fast direction from trench-parallel close to the trench to trench-perpendicular farther inland; this is observed very clearly at Hokkaido stations and is also present in the transition from northern Ryukyu stations to southern Kyushu stations (Fig. 5). It has been suggested by Karato (2004) that such a rotation could be associated with the spatial variations in water content and/or stress conditions. Karato (2004) hypothesized that the rotation can be explained by simple corner flow in the mantle wedge, in which the primary flow direction is trench-parallel, in combination with so-called "Type B" olivine LPO associated with high stress and/or high $\mathrm{H}_{2} \mathrm{O}$ content (Jung and Karato, 2001) close to the trench. Farther away from the trench, either the mantle material is dehydrated or the prevailing stress conditions are lower, and a "Type A" olivine LPO pattern is established. An alternate hypothesis is that the rotation is associated with complicated flow patterns in the upper mantle, perhaps associated with the kink in the Pacific slab beneath Hokkaido and associated with the confluence of the Pacific and Philippine slabs beneath southern Kyushu. Without further modeling we cannot distinguish between these two hypotheses but we note that the rotation from trenchparallel fast directions close to the trench to trenchperpendicular away from the trench that we observe in our $F$-net dataset has been observed in other subduction systems (e.g., Smith et al., 2001; Margheriti et al., 1996; Nakajima and Hasegawa, 2004), although the opposite trend has also been observed (Levin et al., 2004).

A third striking feature of our splitting dataset is the character of splitting patterns at stations in northern Honshu (Fig. 5). The stations in northern Honshu and southernmost Hokkaido exhibit splitting patterns that are more complicated than a simple anisotropic model 


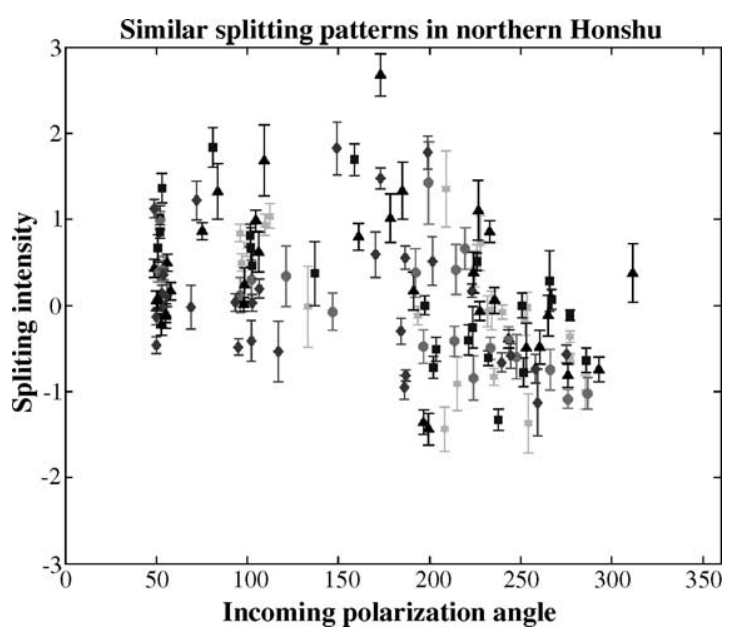

Fig. 8. The splitting vectors for five northern Honshu stations (IYG, GJM, KSN, KSK, and SBT) are plotted with different symbols and shading. Although the splitting patterns are clearly inconsistent with a simple anisotropic model, they are coherent over long length scales.

would allow; however, the patterns at these stations are coherent over long spatial length scales (shown in Fig. 8). The splitting patterns obtained using the Chevrot (2000) method exhibit significant departure from a simple $\sin (2 \theta)$ variation; in fact, a $\sin (\theta)$ periodicity seems to dominate the signal. This may indicate the presence of a dipping axis of anisotropic symmetry (Chevrot, 2000; Chevrot and van der Hilst, 2003), but more detailed forward modeling is needed to confirm this interpretation. The presence of a dipping axis of symmetry would be consistent with the dominant tectonic feature beneath this group of stations, the westward-dipping Pacific slab.

Finally, we emphasize that in the region under study a rapid spatial variation in observed splitting patterns is usually correlated with complexity in slab morphology. In locations, where the slab morphology is simple, such as along the Ryukyu arc or beneath northern Honshu, the splitting behavior is generally consistent among stations separated by several hundred kilometers. Sections of the array where splitting behavior changes rapidly between stations separated by $\sim 70 \mathrm{~km}$ or less, such as the Kanto-Tokai region, or where splitting behavior at individual stations is usually more complicated than a simple anisotropic model would allow, such as Hokkaido, are generally located above areas of complicated slab morphology (Fig. 5). This correspondence provides support for the idea that complicated slab morphology may induce complex upper mantle flow patterns, which in turn manifest themselves as rapid spatial variations in shear wave splitting behavior.

\subsection{Implications for other subduction zones}

Our investigation has shown that the majority of $F$-net stations exhibit variations in measured splitting parameters with backazimuth and/or incoming polarization direction that are inconsistent with a simple anisotropic model. We emphasize the danger of interpreting a single splitting measurement at one of these stations in terms of mantle anisotropy. For stations with complicated splitting patterns, the splitting parameters inferred from a single $S K(K) S$ or teleseismic $S$ wave arrival can be misleading and the interpretation must be based on of a large number of measurements covering a range of backazimuths and/or incoming polarization azimuths. At $F$-net stations, complicated splitting patterns at individual stations are commonplace; in fact, stations that exhibit splitting patterns consistent with a simple anisotropic model are the exception rather than the rule. It seems likely that complex splitting is common in other subduction zones and in other tectonically complicated regions. Therefore, caution should be exercised when interpreting a single splitting measurement in terms of upper mantle anisotropy at stations that overlie complex tectonic structure.

\subsection{Comparison with previous studies}

Two recent studies have investigated the splitting of local $S$ phases due to upper mantle anisotropy at Japanese stations. Smith and Fouch (submitted for publication) used data from local slab events beneath a subset of the $F$-net stations, while Nakajima and Hasegawa (2004) exploited data from shallow and intermediate-depth earthquakes measured at shortperiod stations of the Hi-net array, which is also operated by NIED. A direct comparison of local and teleseismic splitting is difficult, but we find several points of agreement between the main features of our dataset and these two studies.

The work of Smith and Fouch (submitted for publication) focused on a subset of the $F$-net network and covered the area from roughly 32 to $36^{\circ} \mathrm{N}$ and 134 to $138^{\circ} \mathrm{W}$ (see Fig. 1). Their dataset covers events 
with hypocentral depths ranging from approximately $25 \mathrm{~km}$ to nearly $500 \mathrm{~km}$. The three main features of their dataset that are consistent with our work are as follows. First, they find fast directions that trend consistently NW-SE at a group of stations in the southern KantoTokai region (OHS, KNY, and NAA). We find similar NW-SE fast directions at stations KNY and NAA, as well as nearby stations HKW and KNM. Secondly, they identify a region to the southwest of the NW-SE trending fast directions where fast directions trend approximately perpendicular, to the SW-NE. This is consistent with our results for stations TGA and ISI in this region. Finally, Smith and Fouch (submitted for publication) note a consistent increase in the measured splitting time with increasing hypocenter depth, with the largest split times (associated with events from 400 to $500 \mathrm{~km} \mathrm{depth)}$ of approximately $1 \mathrm{~s}$. Although we lack such depth resolution, their results for deep events are quite consistent with the average split times we obtain from teleseismic events at the stations in their study region, which range from $\sim 0.6 \mathrm{~s}$ to $\sim 1.0 \mathrm{~s}$.

The work of Nakajima and Hasegawa (2004) focuses on a region beneath the southern part of Tohuku, covering the area from roughly 36 to $39^{\circ} \mathrm{N}$ and 138 to $142^{\circ} \mathrm{E}$. The station density for the Hi-net network is far higher than for $F$-net; there are only $9 F$-net stations located in the Nakajima and Hasegawa (2004) study area compared to approximately $75 \mathrm{Hi}$-net stations. Moreover, they only consider data from relatively shallow earthquakes, and thus presumably sample the crust and lithosphere only. Notwithstanding these differences, we can make a few observations. First, the Nakajima and Hasegawa (2004) study reveals a striking rotation of fast directions from trench-parallel closer to the trench to trench-parallel farther away from the trench, which is similar to the results obtained in the present study for other areas. This pattern is difficult to discern in our $F$-net results for the southern Tohuku region, perhaps due to the paucity of stations. At the four $F$-net stations in this region for which we obtained reliable fast directions we identified a SW-NE trending fast direction (trench-parallel) for station CHS and NW-SE trending fast direction (trench-perpendicular) at stations HRO, ONS, and KZK. This is consistent with the results of Nakajima and Hasegawa (2004). Secondly, we note that the split times we obtained for stations in this region for teleseismic phases $(\sim 0.5-0.9 \mathrm{~s})$ are considerably larger than the highest split times ob- tained by Nakajima and Hasegawa (2004) (0.1-0.4 s). This discrepancy highlights the greater sensitivity to crustal anisotropy in the Shimizu et al. dataset.

\section{Future work}

We emphasize that the interpretations of the data presented in this paper should be considered as preliminary. We have assembled a large dataset for shear wave splitting and have thoroughly investigated the dependence of measured values for $(\varphi, \delta t)$ on parameters such as incoming polarization azimuth, but the interpretation of splitting parameters is difficult and inherently non-unique, especially in the presence of complex anisotropic structure. However, we believe that our dataset affords us a chance to characterize more quantitatively the three-dimensional structure of the upper mantle. By bringing to bear more sophisticated forward (numerical modeling of geodynamic processes in the mantle wedge and beneath the slab) and inverse (the inversion of shear wave splitting measurements for three-dimensional anisotropic structure) techniques, we will more fully exploit the splitting dataset we have assembled.

\section{Summary}

We have assembled and processed a large database of teleseismic shear wave $(S, S K S$, and $S K K S$ ) splitting measurements for the broadband $F$-net array in Japan. For each station we analyzed records covering a wide range of incoming polarization azimuths and incidence angles, and we looked for variations in measured splitting parameters that could be indicative of complex anisotropic structure. Most of the $F$-net stations exhibit splitting behavior that is more complicated than a simple, homogenous, single-layer anisotropic model would allow. We observe two endmember scenarios for geographical variations in splitting behavior. In some parts of the array, most notably the Ryukyu arc, we observe splitting behavior that is consistent between stations over a distance of approximately $700 \mathrm{~km}$. In other parts of the array, most notably the Kanto-Tokai region, splitting behavior changes rapidly, with stations separated by as little as $70 \mathrm{~km}$ exhibiting completely different splitting patterns. We cannot rule out a lithospheric contribution but our observations seem most 

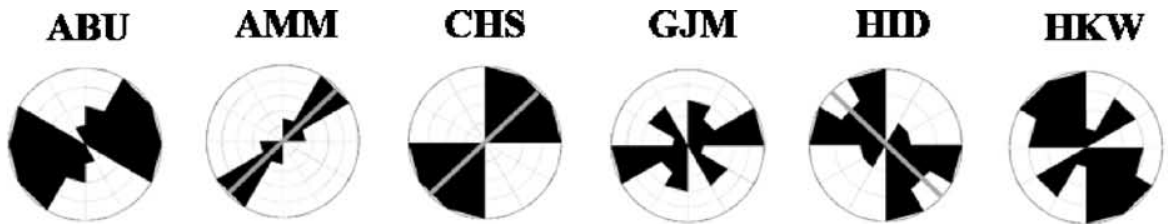

HRO

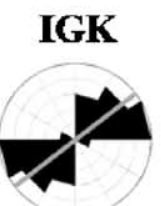

IMG

INN

ISI

IYG

IZH
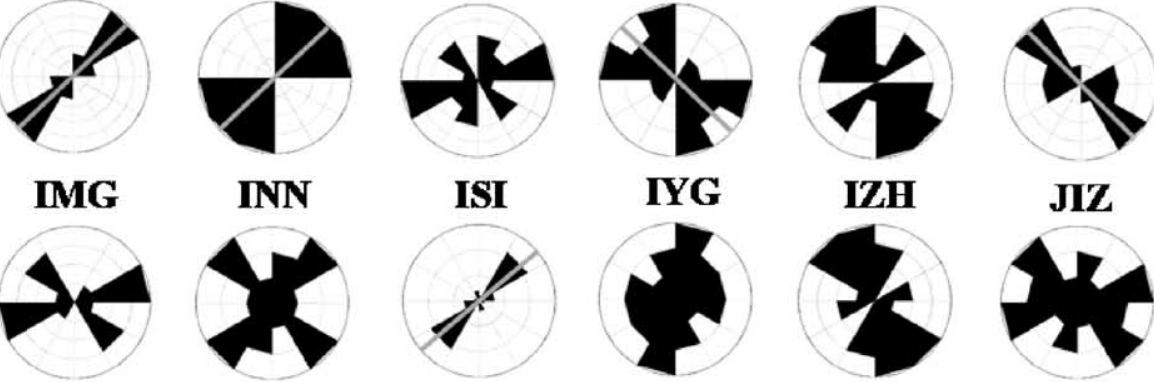

JIZ
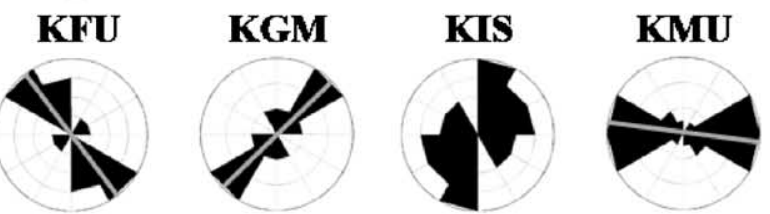

KNM

KNP
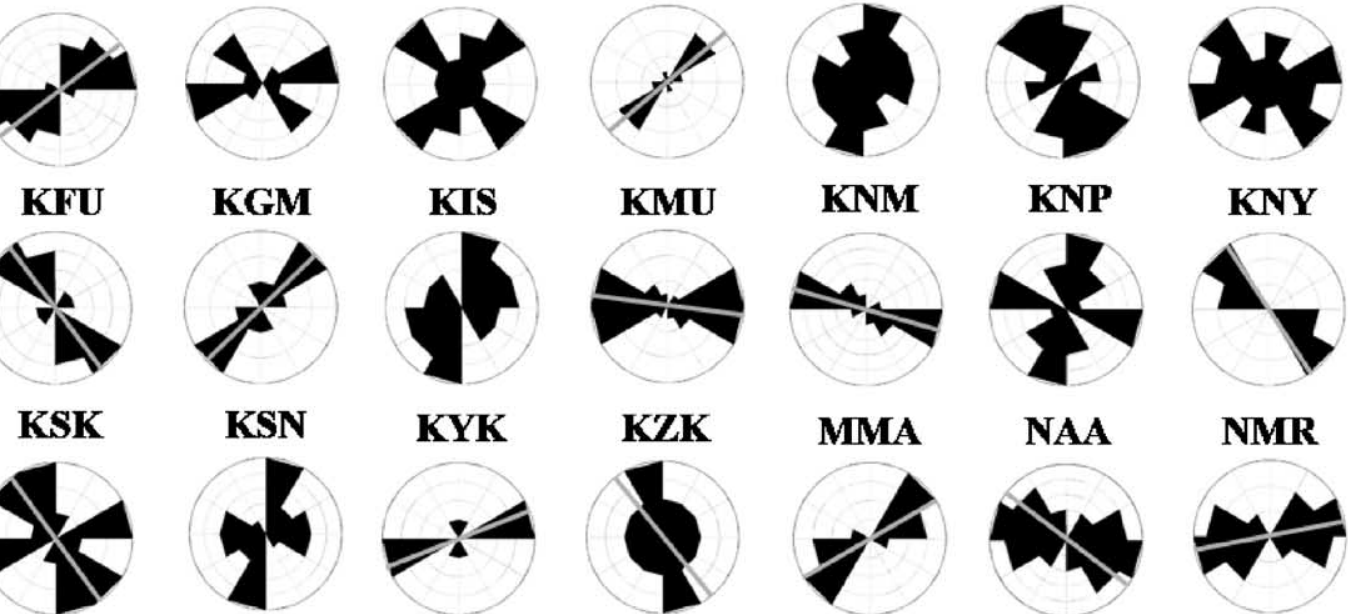

KNY
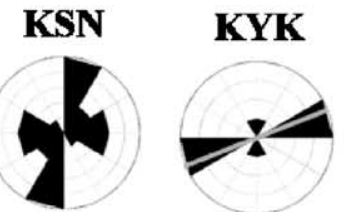

KZK

MMA

NAA
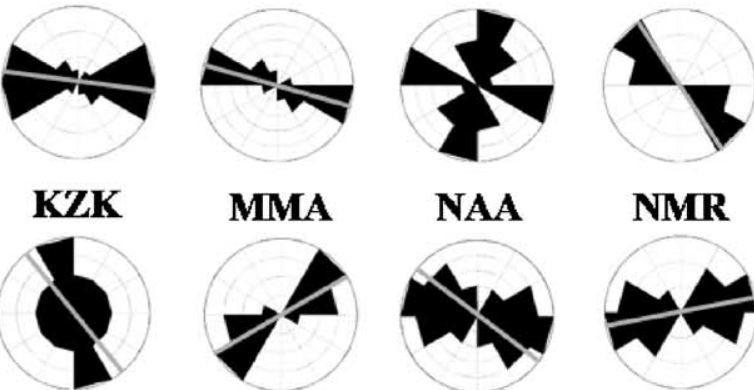

NMR
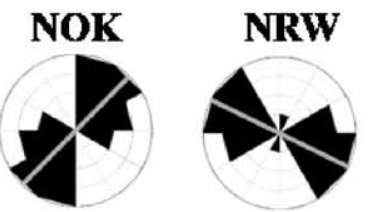

NSK
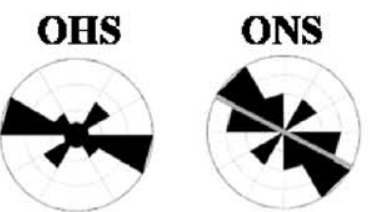

SBR
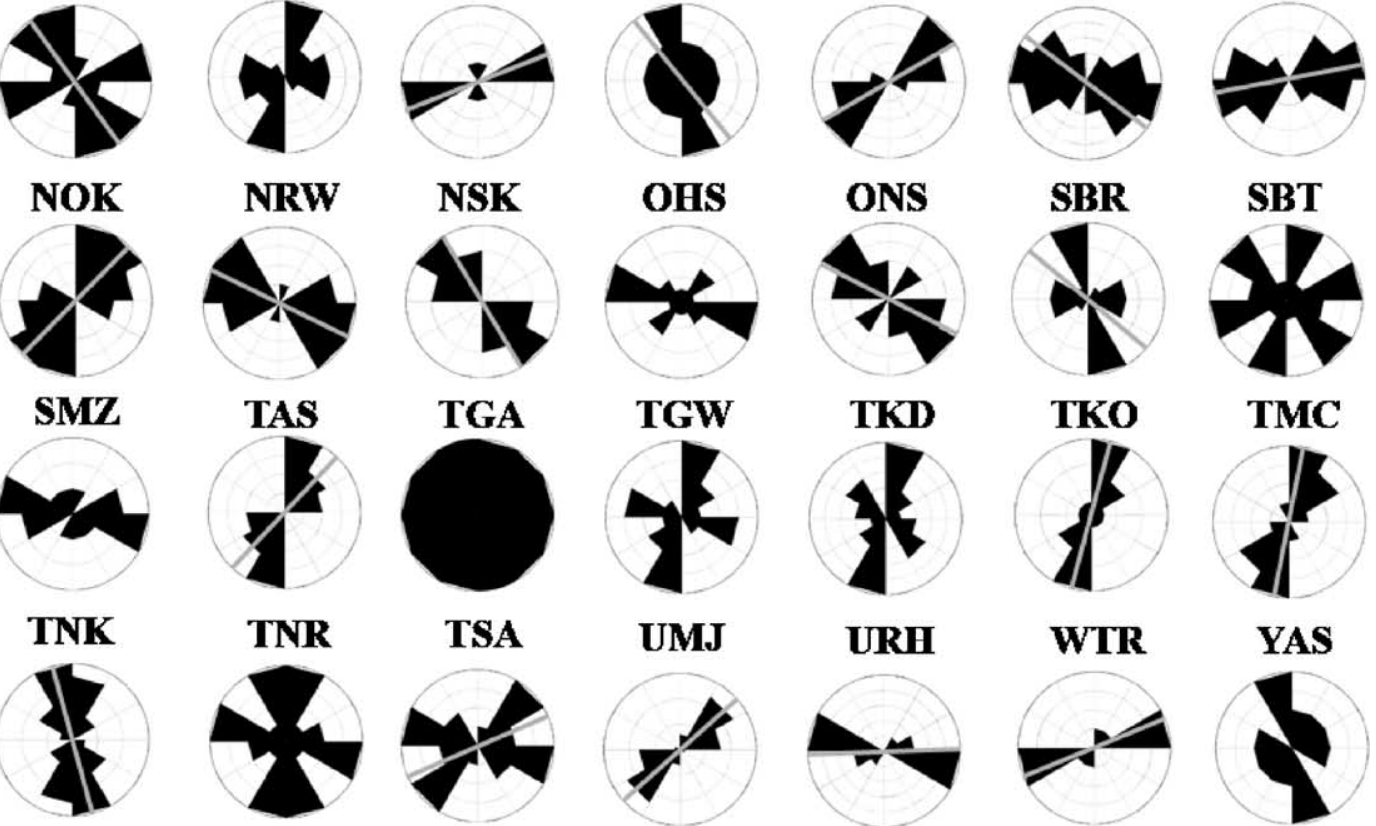

UMJ
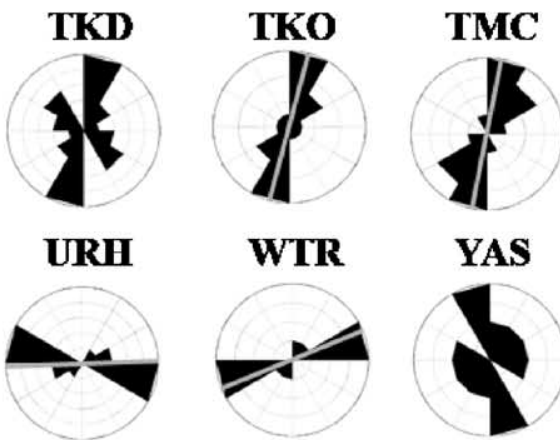

YMZ
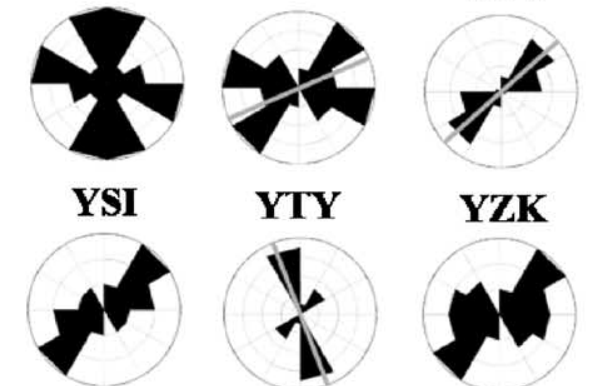

WTR

YAS

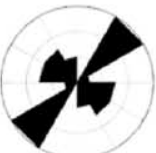

YZK

ZMM
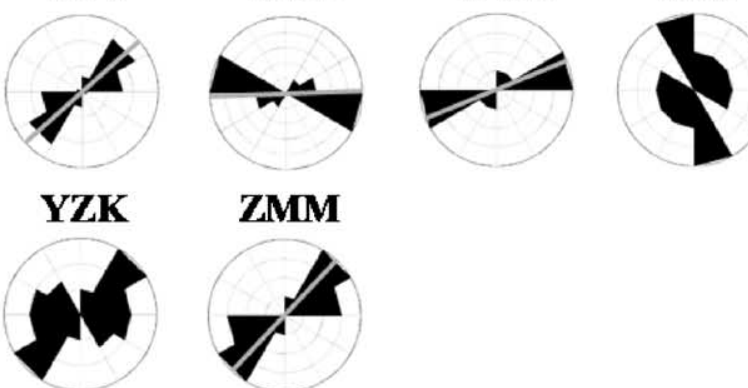

Fig. A.1. Rose diagrams showing the distribution of fast directions measured with the cross-correlation method at $55 F$-net stations. For stations in Category I and Category II, the best-fitting fast direction found with the Chevrot (2000) method is marked with a gray line. For station locations, categorizations, and best-fitting splitting parameters, see Table A.1. Stations with poor data quality (IWT, TTO, and TYM) are not shown on this figure; rose diagrams for stations TKA, SGN, TMR, FUJ, FUK, and HSS are shown in Fig. 4. 
consistent with significant complexity in anisotropic structure in the asthenospheric upper mantle beneath much of Japan. Our observations allow several preliminary interpretations in terms of tectonic processes, but the long-term goal of this work is to combine geodynamical modeling and inversion of shear wave splitting measurements to obtain a quantitative model of the three-dimensional anisotropic structure beneath Japan.

\section{Acknowledgements}

The authors thank the Japanese National Research Institute for Earth Science and Disaster Prevention for making $F$-net data available and easily accessible, Sebastien Chevrot for assistance with data processing and for providing his splitting codes, and Bill Menke for making his cross-correlation code freely available. The comments of an anonymous reviewer greatly improved the manuscript. This research was supported by NSF grant EAR-0337697 and by an NSF Graduate Research Fellowship awarded to M.D.L.

\section{Appendix A}

Here, we provide a summary of our splitting measurements at all stations. In Fig. A.1, we plot circular histograms (rose diagrams) showing the distribution of fast directions measured with the cross-correlation method. For all stations in Category I and Category II, the average fast direction measured with the Chevrot (2000) method is shown with a gray line. Table A.1 provides station coordinates for all stations as well as best-fitting splitting parameters $(\varphi, \delta t)$ for stations in Category I and Category II.

Table A.1

Station coordinates for $F$-net stations, along with best-fitting splitting parameters for all Category I and Category II stations

\begin{tabular}{lllll}
\hline Station name & Lat & Lon & $\varphi\left(^{\circ}\right)$ & $\delta t(\mathrm{~s})$ \\
\hline Category I & & & & \\
AMM & 28.15 & 129.30 & 46 & 0.65 \\
FUK & 32.71 & 128.76 & -59 & 1.13 \\
HRO & 37.22 & 140.88 & -46 & 0.38 \\
IGK & 24.41 & 124.18 & 53 & 1.10 \\
KFU & 35.75 & 138.57 & -34 & 0.79 \\
KGM & 26.75 & 128.22 & 47 & 0.58
\end{tabular}

Table A.1 (Continued)

\begin{tabular}{lllll}
\hline Station name & Lat & Lon & $\varphi\left({ }^{\circ}\right)$ & $\delta t(\mathrm{~s})$ \\
\hline ONS & 36.15 & 138.98 & -64 & 0.78 \\
TAS & 31.19 & 130.91 & 45 & 0.75 \\
TKA & 31.51 & 130.79 & 52 & 0.63 \\
UMJ & 33.57 & 134.04 & 56 & 0.78 \\
URH & 42.93 & 143.67 & 87 & 0.68 \\
WTR & 34.37 & 136.58 & 70 & 0.56 \\
YTY & 34.28 & 131.04 & -20 & 0.73 \\
ZMM & 26.23 & 127.31 & 45 & 0.55 \\
Category II & & & & \\
CHS & 35.70 & 140.86 & 43 & 0.73 \\
HID & 42.82 & 143.41 & -50 & 0.28 \\
HSS & 42.96 & 141.23 & -37 & 0.78 \\
ISI & 34.06 & 134.46 & 50 & 0.33 \\
KMU & 42.24 & 142.97 & -79 & 0.59 \\
KNM & 35.72 & 137.18 & -74 & 1.10 \\
KNY & 34.87 & 138.07 & -31 & 0.26 \\
KSK & 38.25 & 140.59 & -34 & 0.41 \\
KYK & 30.37 & 130.41 & 71 & 0.37 \\
KZK & 37.30 & 138.52 & -38 & 0.34 \\
MMA & 41.16 & 140.41 & 59 & 0.38 \\
NAA & 35.22 & 137.37 & -48 & 0.39 \\
NMR & 43.37 & 145.75 & 80 & 0.72 \\
NOK & 34.14 & 135.35 & 45 & 0.45 \\
NRW & 34.76 & 133.53 & -64 & 1.09 \\
NSK & 34.34 & 132.00 & -30 & 0.39 \\
SGN & 35.51 & 138.95 & -48 & 0.54 \\
SBR & 33.50 & 130.26 & -49 & 0.38 \\
TKO & 31.89 & 131.23 & 16 & 0.33 \\
TMC & 32.60 & 130.92 & 11 & 1.40 \\
TNK & 44.78 & 142.08 & -13 & 0.54 \\
TSA & 33.17 & 132.82 & 71 & 0.27
\end{tabular}

Category III

$\begin{array}{lll}\text { ABU } & 34.86 & 135.57\end{array}$

$\begin{array}{lll}\text { ASI } & 36.65 & 139.42\end{array}$

$\begin{array}{lll}\text { FUJ } & 35.23 & 138.42\end{array}$

$\begin{array}{lll}\text { GJM } & 39.95 & 140.12\end{array}$

$\begin{array}{lll}\text { HKW } & 35.09 & 138.14\end{array}$

$\begin{array}{lll}\text { IMG } & 42.39 & 140.14\end{array}$

$\begin{array}{lll}\text { INN } & 33.47 & 131.31\end{array}$

$\begin{array}{lll}\text { IYG } & 40.12 & 141.59\end{array}$

$\begin{array}{lll}\text { IZH } & 34.13 & 129.21\end{array}$

$\begin{array}{lll}\text { JIZ } & 34.91 & 139.00\end{array}$

$\begin{array}{lll}\text { KIS } & 33.86 & 135.89\end{array}$

$\begin{array}{lll}\text { KNP } & 43.76 & 143.71\end{array}$

KSN $\quad 38.97 \quad 141.53$

$\begin{array}{lll}\text { OHS } & 34.68 & 138.01\end{array}$

$\begin{array}{lll}\text { SBT } & 37.97 & 139.45\end{array}$

$\begin{array}{lll}\text { SMZ } & 34.99 & 138.52\end{array}$

$\begin{array}{lll}\text { TGA } & 35.18 & 136.34\end{array}$

$\begin{array}{lll}\text { TGW } & 33.97 & 132.93\end{array}$

$\begin{array}{lll}\text { TKD } & 32.81 & 131.39\end{array}$

$\begin{array}{lll}\text { TMR } & 41.10 & 141.39\end{array}$

$\begin{array}{lll}\text { TNR } & 34.91 & 137.89\end{array}$ 
Table A.1 (Continued)

\begin{tabular}{lllll}
\hline Station name & Lat & Lon & $\varphi\left({ }^{\circ}\right)$ & $\delta t(\mathrm{~s})$ \\
\hline YAS & 35.65 & 135.16 & & \\
YMZ & 36.92 & 140.25 & & \\
$\quad$ YSI & 35.19 & 132.89 & & \\
YZK & 35.09 & 134.46 & \\
Category IV & & & \\
$\quad$ IWT & 35.93 & 139.74 & \\
TTO & 35.83 & 138.12 & \\
TYM & 34.97 & 139.84 & \\
\hline
\end{tabular}

\section{References}

Alsina, D., Snieder, R., 1995. Small-scale sublithospheric continental mantle deformation: constraints from SKS splitting observations. Geophys. J. Int. 123, 431-448.

Ando, M., Ishikawa, Y., Yamazaki, F., 1983. Shear wave polarization anisotropy in the upper mantle beneath Honshu, Japan. J. Geophys. Res. 88, 5850-5864.

Babuška, V., Cara, M., 1991. Seismic anisotropy in the Earth. Modern Approaches in Geophysics, vol. 10. Kluwer Academic Publishers, Dordrecht, The Netherlands.

Chevrot, S., 2000. Multichannel analysis of shear wave splitting. J. Geophys. Res. 105, 21579-21590.

Chevrot, S., van der Hilst, R.D., 2003. On the effects of a dipping axis of symmetry on shear wave splitting measurements in a transversely isotropic medium. Geophys. J. Int. 152, 497505.

Christensen, N.I., 1984. The magnitude, symmetry and origin of upper mantle anisotropy based on fabric analyses of ultramafic tectonites. Geophys. J. R. Astron. Soc. 76, 89-111.

Crampin, S., 1977. Seismic anisotropy, a summary. J. Geophys. - Z. Geophys. 43, 499-501.

Engdahl, E.R., van der Hilst, R.D., Buland, R.P., 1998. Global teleseismic earthquake relocation with improved travel times and procedures for depth determination. Bull. Seism. Soc. Am. 88, 722-743.

Favier, N., Chevrot, S., 2003. Sensitivity kernels for shear wave splitting in transverse isotropic media. Geophys. J. Int. 153, 213-228.

Fischer, K.M., Fouch, M.J., Wiens, D.A., Boettcher, M.S., 1998. Anisotropy and flow in Pacific subduction zone back-arcs. Pure Appl. Geophys. 151, 463-475.

Fischer, K.M., Parmentier, E.M., Stine, A.R., Wolf, E.R., 2000. Modeling anisotropy and plate-driven flow in the Tonga subduction zone back arc. J. Geophys. Res. 105, 16181-16191, 191.

Fischer, K.M., Wiens, D.A., 1996. The depth distribution of mantle anisotropy beneath the Tonga subduction zone. Earth Planet. Sci. Lett. 142, 253-260.

Fischer, K.M., Yang, X., 1994. Anisotropy in Kuril-Kamchatka subduction zone structure. Geophys. Res. Lett. 21, 5-8.

Forsyth, D.W., 1975. The early structural evolution and anisotropy of the oceanic upper mantle. Geophys. J. R. Astron. Soc. 43, $103-162$.
Fouch, M.J., Fischer, K.M., 1996. Mantle anisotropy beneath northwest Pacific subduction zones. J. Geophys. Res. 101, 15987-16002.

Fryer, G.J., Frazer, L.N., 1984. Seismic waves in stratified anisotropic media. Geophys. J. R. Astron. Soc. 78, 691-710.

Fryer, G.J., Frazer, L.N., 1987. Seismic waves in stratified anisotropic media. II. Elastodynamic eigensolutions for some anisotropic systems. Geophys. J. R. Astron. Soc. 91, 73-101.

Fukao, Y., 1984. Evidence from core-reflected shear waves for anisotropy in the Earth's mantle. Nature 309, 695-698.

Fukao, Y., Obayashi, M., Inoue, H., Nenbai, M., 1992. Subducting slabs stagnant in the mantle transition zone. J. Geophys. Res. 97, 4809-4822.

Gudmundsson, O., Sambridge, M., 1998. A regionalized upper mantle (RUM) seismic model. J. Geophys. Res. 103, 71217136.

Hartog, R., Schwartz, S.Y., 2000. Subduction-induced strain in the upper mantle east of the Mendocino triple junction, California. J. Geophys. Res. 105, 7909-7930.

Hess, H.H., 1964. Seismic anisotropy of the uppermost mantle under oceans. Nature 203, 629-630.

Hiramatsu, Y., Ando, M., 1996. Seismic anisotropy near source region in subduction zones around Japan. Phys. Earth Planet. Inter. 95, 237-250.

Holtzman, B.K., Kohlstedt, D.L., Zimmerman, M.E., Heidelbach, F., Hiraga, T., Hustoft, J., 2003. Melt segregation and strain partitioning: implications for seismic anisotropy and mantle flow. Science 301, 1227-1230.

Iidaka, T., Obara, K., 1997. Seismological evidence for the existence of aniosotropic zone in the metastable wedge inside the subducting Izu-Bonin slab. Geophys. Res. Lett. 24, 33053308.

Jung, H., Karato, S.-I., 2001. Water-induced fabric transitions in olivine. Science 293, 1460-1463.

Kaminski, E., Ribe, N.M., 2001. A kinematic model for recrystallization and texture development in olivine polycrystals. Earth Planet. Sci. Lett. 189, 253-267.

Kaneshima, S., 1990. Origin of crustal anisotropy; shear wave splitting studies in Japan. J. Gephys. Res. 95, 11121-11133.

Karato, S., 2004. Mapping water content in the upper mantle. In: Eiler, J.M. (Ed.), Inside the Subduction Factory. Am. Geophys. Union, Geophys. Monogr. Ser., vol. 138.

Kennett, B.L.N., Engdahl, E.R., 1991. Traveltimes for global earthquake location and phase identification. Geophys. J. Int. 105, 429-465.

Levin, V., Droznin, D., Park, J., Gordeev, E., 2004. Detailed mapping of seismic anisotropy with local shear waves in southeastern Kamchatka. Geophys. J. Int. 158, 1009-1023.

Levin, V., Menke, W., Park, J., 1999. Shear wave splitting in the Appalachians and the Urals: a case for multilayered anisotropy. J. Geophys. Res. 104, 17975-17993.

Levin, V., Menke, W., Park, J., 2000. No regional anisotropic domains in the northeastern U.S. Appalachians. J. Geophys. Res. 105, 19029-19042.

Long, M.D., van der Hilst, R. D. Estimating shear wave splitting parameters from broadband recordings: a comparison of three methods, Bull. Seism. Soc. Am., in press. 
Margheriti, L., Nostro, C., Cocco, M., Amato, A., 1996. Seismic anisotropy beneath the Northern Apennines (Italy) and its tectonic implications. Geophys. Res. Lett. 23, 2721-2724.

Meade, C., Silver, P.G., Kaneshima, S., 1995. Laboratory and seismological observations of lower mantle isotropy. Geophys. Res. Lett. 22, 1293-1296.

Mehl, L., Hacker, B.R., Hirth, G., Kelemen, P.B., 2003. Arc-parallel flow within the mantle wedge: evidence from the accreted Talkeetna arc, south central Alaska. J. Geophys. Res. 108 (2375) (doi:10.1029/2002JB002233).

Nakajima, J., Hasegawa, A., 2004. Shear-wave polarization anisotropy and subduction-induced flow in the mantle wedge of northern Japan. Earth Planet. Sci. Lett. 225, 365-377.

Nicolas, A., Christensen, N.I., 1987. Formation of anisotropy in upper mantle peridotites: a review. In: Fuchs, K., Froidevaux, C. (Eds.), Composition, Structure and Dynamics of the Lithosphere-Asthenosphere System. Am. Geophys. Union, Geodyn. Ser., vol. 16, pp. 111-123.

Niu, F., Perez, A.M., 2004. Seismic anisotropy in the lower mantle: A comparison of waveform splitting of SKS and SKKS. Geophys. Res. Lett. 31, L24612 (doi:10.1029/2004GL021196).

Özaleybey, S., Savage, M.K., 1994. Double-layer anisotropy resolved from S phases. Geophys. J. Int. 117, 653-664.

Park, J., Levin, V., 2002. Seismic anisotropy: tracing plate dynamics in the mantle. Science 296, 485-489.

Park, J., Levin, V., Brandon, M.T., Lees, J.M., Peyton, V., Gordeev, E., Ozerov, A., 2002. A dangling slab, amplified arc volcanism, mantle flow and seismic anisotropy near the Kamchatka plate corner. In: Stein, S., Freymeuller, J. (Eds.), Plate Boundary Zones. Am. Geophys. Union, Geodyn. Ser., vol. 30, pp. 295324.

Peyton, V., Levin, V., Park, J., Brandon, M., Lees, J., Gordeev, E., Ozerov, A., 2001. Mantle flow at a slab edge; seismic anisotropy in the Kamchatka region. Geophys. Res. Lett. 28, 379-382.
Russo, R.M., Silver, P.G., 1994. Trench-parallel flow beneath the Nazca Plate from seismic anisotropy. Science 263, 1105-1111.

Saltzer, R.L., Gaherty, J., Jordan, T.H., 2000. How are vertical shear wave splitting measurements affected by variations in the orientation of azimuthal anisotropy with depth? Geophys. J. Int. 141, 374-390.

Savage, M.K., 1999. Seismic anisotropy and mantle deformation: What have we learned from shear wave splitting? Rev. Geophys. $37,65-106$.

Silver, P.G., 1996. Seismic anisotropy beneath the continents: probing the depths of geology. Annu. Rev. Earth Planet. Sci. 24, 385-432.

Silver, P.G., Savage, M.K., 1994. The interpretation of shear-wave splitting parameters in the presence of two anisotropic layers. Geophys. J. Int. 119, 949-963.

Simons, F.J., van der Hilst, R.D., 2003. Seismic and mechanical anisotropy and the past and present deformation of the Australian lithosphere. Earth Planet. Sci. Lett. 211, 271-286.

Smith, C.M.B., Fouch, M.J. Shear wave splitting and mantle flow beneath Japan, Earth Planet. Sci. Lett., submitted for publication.

Smith, G.P., Wiens, D.A., Fischer, K.M., Dorman, L.M., Webb, S.C., Hildebrand, J.A., 2001. A complex pattern of mantle flow in the Lau Backarc. Science 292, 713-716.

Tommasi, A., Mainprice, D., Canova, G., Chastel, Y., 2000. Viscoplastic self-consistent and equilibrium-based modeling of olivine lattice preferred orientations: implications for the upper mantle seismic anisotropy. J. Geophys. Res. 105, 7893-7908.

van der Hilst, R., Engdahl, R., Spakman, W., Nolet, G., 1991. Tomographic imaging of subducted lithosphere below northwest Pacific island arcs. Nature 353, 37-43.

Vidale, J.E., 1986. Complex polarization analysis of particle motion. Bull. Seism. Soc. Am. 71, 1511-1530.

Zhang, S., Karato, S.-I., 1995. Lattice preferred orientation of olivine aggregates deformed in simple shear. Nature 415, 777-780. 